\title{
PRODUCTION OF BIOMASS FROM WHEY PERMEATE AND STARCH HYDROLYSATES \\ BY Saccharomyces cerevisiae AND Kluyveromyces marxianus
}

(Received: 8.9.2008)

\author{
By \\ J. S. Haddadin \\ Department of Nutrition and Food Industries, College of Agriculture, \\ University of Mu'tah, Mu'tah, Karak, Jordan
}

\begin{abstract}
Three local strains of Saccharomyces cerevisiae (Sc 1, Sc 2 and Sc 3) and one strain of Kluyveromyces marxianus were used as pure or mixed cultures in a commercial medium, in order to compare their kinetic parameters and fermentation patterns. It was found that $S$. cerevisiae Sc 3 had the highest maximum specific growth rates on glucose $\left(0.32 \mathrm{~h}^{-1}\right)$ and on ethanol $\left(0.11 \mathrm{~h}^{-1}\right)$. The yields of biomasses on glucose and on ethanol were the most important. A low yield of ethanol on glucose 0.33 $(\mathrm{g} / \mathrm{g})$ was obtained. Kinetic studies of continuous production of biomass from a mixture of whey permeate and starch hydrolysates using mixed culture of Saccharomyces cerevisiae Sc 3 and Kluyveromyces marxianus were performed. In the course of continuous culture on mixed substrate of whey permeate and starch hydrolysates "A", Kluyveromyces marxianus overgrew Saccharomyces cerevisiae. Whereas in the course of continuous culture on mixed substrate of whey permeate and starch hydrolysates "B" there was a stabilization of the coculture (Saccharomyces cerevisiae Sc 3 and Kluyveromyces marxianus).
\end{abstract}

Key words: biomass production, Kluyveromyces marxianus, Saccharomyces cerevisiae, starch hydrolysates, whey permeate.

\section{INTRODUCTION}

The rapid increase in the worldwide population and the limited reserves in the conventional plant proteins, have stimulate research for new protein sources.

It is possible to produce proteins in the industrial scale from unicellular organisms, notably from yeast. This way of production presents triple interest: 1) it is independent from the climate nature or the soil quality, 2) it has rapid production rate and a continuous production process can be used and 3) the substrates for the fermentation is abounding and not very costly because these basically are by-products of various industries: starches, molasses of sugar beet, sulfite liqueurs from paper mill, lactoserum of dairy industries. Among the main agro-industrial wastes, whey and starch are of prime importance (Compango et al., 1995). Whey waste is a major problem for the dairy industry (Ghaly and Kamal, 2004). Finding alternative means to reduce its pollution potential and produce high value-added bio-ingredients has been attempted by many researchers. Kluyveromyces marxianus var. marxianus is a dairy yeast that produces betagalactosidase, allowing for whey fermentation
(Lukondeh et al., 2005; Schultz et al., 2006). Also, $K$. marxianus has been proposed as a source of oligonucleotides, oligosaccharides, and oligopeptides (Belem and Lee, 1998). Paul et al. (2002) determined the nutritional profile of food yeast $K$. fragilis grown on deproteinized whey supplemented with $0.8 \%$ diammonium hydrogen phosphate and 10 ppm indole-3-acetic acid. Starch is present in a number of reserve organs of plants, cereals such as wheat, corn, barley and the tubercles such as potato and manioc. The yeast Saccharomyces cerevisiae could not utilize directly the starch. For this reason the starch should be hydrolyzed to release easily assimilated sugars by yeast prior to the use as a substrate. The hydrolysates contain glucose, maltose, oligosaccharides and polysaccharides in a proportion depending on the nature of the utilized enzyme and the degree of hydrolysis. The transformation of whey permeate and starch to feed yeast is an interesting process due to the good nutritional value of yeasts (Lukondeh et al., 2003 and Schultz et al., 2006). However, it has been observed that in aerated cultures of $K$. fragilis and $K$. lactis a change in cellular metabolism from oxidative to a mixed oxidative-fermentative state 
can occur. This change causes the production of by-metabolic products such as alcohol, aldehydes, esters, etc., which reduce the yields of biomass from whey (Beausejour et al., 1981; CristianiUrbina et al., 1997; Inchaurrondo et al., 1994). To avoid this undesirable effect, the mixed yeast culture has been used Carlotti et al., 1991 and Cristiani-Urbina et al., 2000). It is necessary to note that the major part of the industrial techniques concerning the production of food grade yeast, always rest on a pure culture of a given kind of microorganism.

The objectives of this work was 1) to test several local strains of Saccharomyces cerevisiae to choose a strain that has suitable physiological characteristics such as high biomass production, high yield and produced limited quantity of ethanol. 2) To study the influences of the composition of the whey permeate on the growth of the selected S. cerevisiae. 3) To detect the effect of glucose (starch hydrolysates) on lactose assimilation by $K$. marxianus. 4) To develop a continuous fermentation process to produce cheap proteins implicating two strains of yeast allowed in the food industry, growing on a mixed substrate constituted of whey permeate and starch hydrolysates.

\section{MATERIALS AND METHODS \\ 2.1. Micro-organisms}

Three strains of Saccharomyces cerevisiae ( $\mathrm{Sc}$ $1, \mathrm{Sc} 2$, and Sc 3) and one strain of Kluyveromyces marxianus were used. The Kluyveromyces marxianus was isolated from Jordanian dairy products; however, Saccharomyces cerevisiae strains were obtained from brewing industries in Amman area/Jordan. The yeasts were maintained slants containing Yeast-Malt media: yeast extract $3 \mathrm{~g} / \mathrm{l}$, malt extract $3 \mathrm{~g} / \mathrm{l}$, peptone $5 \mathrm{~g} / \mathrm{l}$, glucose 10 $\mathrm{g} / \mathrm{l}$ (Scharlau microbiology).

\subsection{Fermentation media}

Different types of fermentation media have been used and prepared from Yeast Nitrogen Base or Y.N.B. (Difco) supplemented with different carbon sources: (1)concentrated whey permeate coming from the factory of the University of Mutah south of Jordan. 2) Two different starch hydrolysates A and B were coming from distillery. The sugar composition of hydrolysate A is $97.0 \%$ of glucose, $1.0 \%$ of maltose, $1.5 \%$ of maltotrioses and $0.5 \%$ of polysaccharides. The sugar composition of hydrolysate $\mathrm{B}$ is $47.7 \%$ of glucose, $43.6 \%$ of maltose, 1.9 of maltotrioses and $6.6 \%$ of polysaccharides. The sterilization of hydrolysates was performed by ultra-filtration at $0.2 \mu \mathrm{m}$.

\subsection{Experimental design}

Subcultures were performed in Erlenmeyer flasks, whereas for the batch and continuous cultures, the experiments were performed in $2 \mathrm{~L}$ bioreactor. Each of the following experiments was repeated three times and the averages were calculated.

\subsubsection{Batch fermentations}

Tables (1 and 2) present the experimental design of the subcultures and of batch cultures, respectively. The subcultures of $K$. marxianus Table $1\left(\mathrm{~N}^{\circ} 2\right)$ were conducted on two distinct media, one based on glucose (subculture $n^{\circ} 1$ ), the other based on whey permeate (subculture $n^{\circ} 2$ ). Each subculture then served for inoculating a fermentor containing fermentation media composed of whey permeate (lactose) and of glucose Table (2).

Cultures of $S$. cerevisiae Sc 3 were applied to fermentor containing two different media Table 2 $\left(\mathrm{N}^{\circ} 3\right)$. The first medium $\left(\mathrm{C}^{\circ} 1\right)$ constituted of whey permeate associated with glucose as well as Y.N.B in order to make sure of no possible vitamin and amino acid limitation. The second medium $\left(\mathrm{C}^{\circ} 2\right)$ contains only the whey permeate associate with glucose.

\subsubsection{Continuous fermentations}

The operational conditions applied to subcultures of $S$. cerevisiae Sc 3 were as follows: ethanol (5 g/l), Y.N.B. (6.7 g/l), working volume $(100 \mathrm{ml})$, agitation $(250 \mathrm{rpm})$, temperature $(28$ $\left.{ }^{\circ} \mathrm{C}\right), \mathrm{pH}(4.5)$ and total incubation time 48 hours. The operational conditions applied to subcultures of $K$. marxianus were as followed: whey permeate (lactose) $(5 \mathrm{~g} / \mathrm{l})$, yeast extract $(0.5 \mathrm{~g} / \mathrm{l}), \mathrm{FeCl}_{3}(2$ $\mathrm{mg} / \mathrm{l}),\left(\mathrm{NH}_{4}\right)_{2} \mathrm{SO}_{4}(1.5 \mathrm{~g} / \mathrm{l})$, working volume (500 $\mathrm{ml})$, agitation $(800 \mathrm{rpm})$, temperature $\left(30^{\circ} \mathrm{C}\right), \mathrm{pH}$ (4.5) and total incubation time 11 hours .

The plan of the experiment was identical for all the accomplished continuous cultures I, II, III and III-bis. Firstly, a batch culture of $S$. cerevisiae Sc 3 on ethanol was performed with the following conditions: ethanol $(5 \mathrm{~g} / \mathrm{l})$, whey permeate (lactose) $(5 \mathrm{~g} / \mathrm{l})$, yeast extract $(0.5 \mathrm{~g} / \mathrm{l}), \mathrm{FeCl}_{3}(2$ $\mathrm{mg} / \mathrm{l}), \quad\left(\mathrm{NH}_{4}\right)_{2} \mathrm{SO}_{4}(1.5 \mathrm{~g} / \mathrm{l})$, polyethylene glycol $(0.5 \mathrm{ml} / \mathrm{l})$, working volume $(1.2 \mathrm{l})$, agitation (800 $\mathrm{rpm})$, aeration $(1 \mathrm{vvm})$, temperature $\left(30^{\circ} \mathrm{C}\right), \mathrm{pH}$ (4.5). As soon as $S$. cerevisiae $S c 3$ has assimilated the available ethanol, continuous culture was then started. The following conditions were used for the continuous I, II, III and III-bis: 
Table (1): The operational conditions applied to the subcultures of the batch fermentations.

\begin{tabular}{|c|c|c|c|c|}
\hline & \multicolumn{4}{|c|}{ Subcultures for the batch fermentations } \\
\hline & \multirow[t]{2}{*}{$\mathbf{N}^{\circ} \mathbf{1}$} & \multicolumn{2}{|c|}{$\mathrm{N}^{\circ} \mathbf{2}$} & \multirow[t]{2}{*}{$\mathbf{N}^{\circ} \mathbf{3}$} \\
\hline & & $\mathbf{n}^{\circ} \mathbf{1}$ & $\mathbf{n}^{\circ} 2$ & \\
\hline Operation conditions & $\begin{array}{l}\text { S. cerevisiae } S c \\
1, S c 2 \text { and } S c 3\end{array}$ & K. marxianus & K. marxianus & $\begin{array}{c}\text { S. cerevisiae } \\
\text { Sc } 3\end{array}$ \\
\hline Glucose $(\mathrm{g} / \mathrm{l})$ & 10 & 10 & - & 10 \\
\hline Whey permeat $(\mathrm{g} / \mathrm{l})$ & - & - & 10 & - \\
\hline YNB $(\mathrm{g} / \mathrm{l})$ & 6.7 & 6.7 & - & 6.7 \\
\hline Y.E. $(\mathrm{g} / \mathrm{l})$ & - & - & 0.5 & - \\
\hline $\mathrm{FeCl}_{3}(\mathrm{mg} / \mathrm{l})$ & - & - & 2 & - \\
\hline$\left(\mathrm{NH}_{4}\right)_{2} \mathrm{SO}_{4}(\mathrm{~g} / \mathrm{l})$ & - & - & 1.5 & - \\
\hline Working volume (ml) & 100 & 100 & 100 & 100 \\
\hline Agitation (rpm) & 250 & 250 & 250 & 250 \\
\hline Temperature $\left({ }^{\circ} \mathrm{C}\right)$ & 28 & 28 & 28 & 28 \\
\hline $\mathrm{pH}$ & 4.5 & 3.5 & 3.5 & 4.5 \\
\hline Duration (h) & 14 & 9 & 9 & 14 \\
\hline
\end{tabular}

Yeast Nitrogen Base $=$ Y.N.B., Yeast Extract $=$ Y.E, $\mathrm{N}^{\circ} 1, \mathrm{~N}^{\circ} 2$ and $\mathrm{N}^{\circ} 3=$ series of experiments for a given microorganism(s).

Table (2): The operational conditions applied to the batch fermentations.

\begin{tabular}{|c|c|c|c|c|}
\hline & \multicolumn{4}{|c|}{ batch fermentations } \\
\hline & \multirow[t]{2}{*}{$\mathbf{N}^{\circ} \mathbf{1}$} & \multirow[t]{2}{*}{$\mathbf{N}^{\circ} \mathbf{2}$} & \multicolumn{2}{|c|}{$\mathbf{N}^{\circ} \mathbf{3}$} \\
\hline & & & $\mathbf{C}^{\circ} \mathbf{1}$ & $\mathbf{C}^{\circ} \mathbf{2}$ \\
\hline Operation conditions & $\begin{array}{l}\text { S. cerevisiae } \mathrm{Sc} \\
1, \mathrm{Sc} 2 \text { and } \mathrm{Sc} 3\end{array}$ & K. marxianus & $\begin{array}{l}\text { S. cerevisiae } \\
\text { Sc } 3\end{array}$ & $\begin{array}{c}\text { S. cerevisiae } \\
\text { Sc } 3\end{array}$ \\
\hline Glucose $(\mathrm{g} / \mathrm{l})$ & 10 & 5 & 10 & 10 \\
\hline Whey permeat $(\mathrm{g} / \mathrm{l})$ & - & 5 & 10 & 10 \\
\hline YNB $(\mathrm{g} / \mathrm{l})$ & 6.7 & - & 6.7 & - \\
\hline Y.E. $(\mathrm{g} / \mathrm{l})$ & - & 0.5 & - & 0.5 \\
\hline $\mathrm{FeCl}_{3}(\mathrm{mg} / \mathrm{l})$ & - & 2 & - & 2 \\
\hline$\left(\mathrm{NH}_{4}\right)_{2} \mathrm{SO}_{4}(\mathrm{~g} / \mathrm{l})$ & - & 1.5 & - & 1.5 \\
\hline P.P.G $(\mathrm{ml} / \mathrm{l})$ & - & 0.5 & 0.5 & 0.5 \\
\hline Working volume (L) & 1.2 & 1.2 & 1.2 & 1.2 \\
\hline Agitation (rpm) & 600 & 900 & 700 & 700 \\
\hline Temperature $\left({ }^{\circ} \mathrm{C}\right)$ & 30 & 30 & 30 & 30 \\
\hline Aeration (vvm) & 1 & 1 & 1 & 1 \\
\hline $\mathrm{pH}$ & 4.5 & 3.5 & 4.5 & 4.5 \\
\hline
\end{tabular}

culture medium per minute. $\mathrm{N}^{\circ} 1, \mathrm{~N}^{\circ} 2$ and $\mathrm{N}^{\circ} 3=$ series of experiments for a given microorganism(s).

$\mathrm{FeCl}_{3}(2 \mathrm{mg} / \mathrm{l}),\left(\mathrm{NH}_{4}\right)_{2} \mathrm{SO}_{4}(1.5 \mathrm{~g} / \mathrm{l})$, polyethylene glycol $(0.5 \mathrm{ml} / \mathrm{l})$, working volume $(1 \mathrm{l})$, agitation $(800 \mathrm{rpm})$, aeration $(1 \mathrm{vvm})$, temperature $\left(30^{\circ} \mathrm{C}\right)$, $\mathrm{pH}(4.5)$, dilution rate $0.18 \mathrm{~h}^{-1}$, yeast extract $[(0.5$ $\mathrm{g} / \mathrm{l})$ for continuous I, II and III and $(0.1 \mathrm{~g} / \mathrm{l})$ for continuous III-bis]. Mixed substrate was constituted of the whey permeate (lactose) $(5 \mathrm{~g} / \mathrm{l})$ associated either with glucose $(5 \mathrm{~g} / \mathrm{l})$ for continuous-I or with starch hydrolysate A $(5 \mathrm{~g} / \mathrm{l}$ glucose) for continuous-II and or with starch hydrolysate $\mathrm{B}$ ( $3 \mathrm{~g} / \mathrm{l}$ glucose and $3 \mathrm{~g} / \mathrm{l}$ maltose) for continuous-III and III-bis. When a steady state was reached, then $30 \mathrm{ml}$ of a concentrated subculture of $K$. marxianus was added to the fermentor. The method of evaluation of both populations of yeasts is: the method of resistance to the actidione (Van der Walt, 1970) for the continuous-I and the X-Gal method for the continuous-II (Maniatis et al., 1982).

\subsection{Analytical methods}

All analyses were performed in triplicate and the results were reported as means. Cell-free samples (filtration through $0.2 \mu_{\mathrm{m}}$ Millipore membranes) were used to analyse different 
substrates and metabolites of all fermentations. Supernatants were collected and conserved at -18 ${ }^{\circ} \mathrm{C}$ until the time of analysis.

\subsubsection{Kinetics parameters determination}

At each sampling time, cell density was measured after proper dilution by measuring the optical density at $660 \mathrm{~nm}\left(\mathrm{OD}_{660}\right)$ using a spectrophotometer (Shimadzu model UV-120-02). Biomass concentration was also estimated by pipeting $10 \mathrm{ml}$ samples into pre-weighed dry tubes and centrifuging at $12000 \mathrm{~g}$ for $10 \mathrm{~min}$. in refrigerated centrifuge at $+4^{\circ} \mathrm{C}$. After removal of the supernatant, cells were washed (twice) by resuspending in distilled water, centrifuging as previously described. The washed cells were dried in an oven at $104{ }^{\circ} \mathrm{C}$ for $24 \mathrm{~h}$, after which the tubes were re-weighed and the cell dry weights estimated. The determination of maximum specific growth rates and yields were done from the balance equations on the fermentor.

Enumeration of yeast populations was done using the following:

1) Actidione (cycloheximide) method

The inoculation of Petri dishes was accomplished by inclusion of $1 \mathrm{ml}$ of the last dilution of the sample in: 1) $10 \mathrm{ml}$ of Yeast Medium (Y.M.) with agar, 2) $9 \mathrm{ml}$ of Yeast Medium (Scharlau microbiology) with agar, in which $1 \mathrm{ml}$ of a sterile solution of actidione of concentration of $50 \mathrm{mg} / 1$ was added. Petri dishes were incubated at $30^{\circ} \mathrm{C}$ for $48 \mathrm{~h}$. The first series of Petri dishes (Yeast Medium without cycloheximide (Sigma-aldrich) gave the total population of yeast, while the second series (Yeast Medium supplied with actidione) gave the population of Kluyveromyces. By difference between both series the population of Saccharomyces could be assessed (Van der Walt, 1970).

2) X-gal or 5-bromo-4-chloro-3-indolyl $\beta$-Dgalactoside method:

The strains of Saccharomyces and Kluyveromyces were cultivated on Petri dishes, on a medium composed of Yeast Nitrogen Base (Y.N.B) Difco $6.7 \mathrm{~g} / \mathrm{l}$, glucose $10 \mathrm{~g} / \mathrm{l}$, lactose 10 $\mathrm{g} / \mathrm{l}$ and X-gal $40 \mathrm{mg} / \mathrm{l}$ (Fisher BioReagents). The inoculation was made by streaking of $0.1 \mathrm{ml}$ of an appropriate dilution of the sample. Petri dishes were incubated at $30{ }^{\circ} \mathrm{C}$ for $48 \mathrm{~h}$. The colonies of Klyuveromyces were blue while those of Sacchromyces were white (Maniatis et al., 1982).

To determine the sugars in the samples of the yeast culture during fermentation, commercially available enzymatic test kits were used (Boerhinger Mannheim, Germany).
Ethanol and acetic acid determination were measured by gas chromatography, using a DELSI DI-200, with flame ionization detector FID. A column ( $2 \mathrm{~m}$ by $2 \mathrm{~mm}$ ) was packed with porapak Q 80-100 mesh. The injector and detector temperature were $220{ }^{\circ} \mathrm{C}$ and the column oven operated isothermally at $170{ }^{\circ} \mathrm{C}$.

The concentrations of organic acids in the culture broth were determined by using highperformance liquid chromatography (HPLC). A column polypore $\mathrm{H}$. Brownlee was used. The column was eluted at temperature $65{ }^{\circ} \mathrm{C}$ with $0.04 \mathrm{~N}_{2} \mathrm{SO}_{4}$ at a flow rate of $1 \mathrm{ml} / \mathrm{min}$. The injection volume was $40 \mu \mathrm{l}$ with retention time of $10 \mathrm{~min}$. Standards (0.1-0.7 g/l) of pyruvic, formic, citric, malic, and $\alpha$-ketoglutaric acid (Sigma Chemicals) were filtered through a $0.45 \mu \mathrm{m}$ filter prior to injection into the column.

To determine the kinetic parameters of growth, biomass production and yields the following equations were used:

The biomass balance equation for batch fermentation can be expressed as follows:

$r_{x}^{\prime \prime \prime} v=d \frac{(v \cdot x)}{d t}$

$r_{x}^{\prime \prime \prime}, \mathrm{v}$ and $\mathrm{x}$ are biomass formation rate, fermentation volume and biomass concentration, respectively. In batch fermentation the volume, v, is constant then

$r_{x}^{\prime \prime \prime} v=v \cdot d \frac{(x)}{d t}$

If $\mu=\mu_{\max }$, then equation (2) becomes:

$\mu_{\text {max }} . x=d \frac{(x)}{d t}$

Rearrangement of equation (3) will give:

$\mu_{\text {max }} . d t=d \frac{(x)}{x}$

Hence

$\mu_{\text {max }} . t=\ln x-\ln x_{0}$

$\ln x=\ln x_{0}-\mu$

The maximum specific growth rates, $\mu_{\text {max }}$

$\left(\mathrm{h}^{-1}\right), \quad$ is therefore, the slope of the curve $\operatorname{Ln} X=f(t) \cdot X$ and $X_{0}$ are biomass concentration and initial biomass concentration $(\mathrm{g} / \mathrm{l})$, respectively.

The balance equations of glucose, $\mathrm{G}$, in the fermentor will be as follows: 


$$
\begin{aligned}
& -r_{G}{ }^{\prime \prime} V=\frac{d(V G)}{d t} \\
& r_{G}{ }^{\prime \prime \prime}=-\frac{d G}{d t} \ldots \ldots \ldots \ldots \ldots \ldots \ldots \ldots \ldots \ldots \ldots(7) \\
& Y_{X / G}=\frac{r_{x}{ }^{\prime \prime \prime}}{r_{G}{ }^{\prime \prime \prime}}=-\frac{d X}{d G}=\frac{X-X^{0}}{G^{0}-G} \ldots \ldots \ldots \ldots \ldots(8) \\
& X-X^{0}=Y_{X / G^{0}}\left(G^{0}-G\right) \ldots \ldots \ldots \ldots \ldots \ldots \ldots(9)
\end{aligned}
$$

Where $G^{0}, r_{G}^{\prime \prime \prime}$ and $Y_{X / G}$ are the initial glucose concentrations $(\mathrm{g} / \mathrm{l})$, glucose consumption rates (g/l.h) and the yield of biomass on glucose $(\mathrm{g} / \mathrm{g})$, respectively.

The balance equations of ethanol, E (g/l), in the fermentor will be as follows:

First phase: Ethanol production

$$
\begin{aligned}
& -r_{E}{ }^{\prime \prime} V=\frac{d(V E)}{d t} \\
& r_{E}{ }^{\prime \prime \prime}=\frac{d E}{d t} \ldots \ldots \ldots \ldots \ldots \ldots \ldots \ldots \ldots \ldots \ldots \ldots \ldots \ldots \\
& Y_{E / G}=\frac{r_{E}{ }^{\prime \prime \prime}}{r_{G}{ }^{\prime \prime \prime}}=-\frac{d E}{d G}=\frac{E-E^{0}}{G^{0}-G} . \\
& E-E^{0}=Y_{E / G^{0}}\left(G^{0}-G\right) \ldots \ldots \ldots \ldots
\end{aligned}
$$

Where $E^{0}, r_{E}^{\prime \prime \prime}$ and $Y_{E / G}$ are the initial ethanol concentrations $(\mathrm{g} / \mathrm{l})$, ethanol production rate $(\mathrm{g} / \mathrm{l} . \mathrm{h})$ and the yield of ethanol on glucose $(\mathrm{g} / \mathrm{g})$, respectively.

Second phase: Ethanol consumption

$$
\begin{aligned}
& -r_{E}{ }^{\prime \prime \prime} V=\frac{d(V E)}{d t} \\
& r_{E}{ }^{\prime \prime \prime}=-\frac{d E}{d t} . \\
& Y_{X / E}=\frac{r_{X}{ }^{\prime \prime \prime}}{r_{E}^{\prime \prime \prime}}=-\frac{d X}{d E}=\frac{X-X^{0^{\prime}}}{E^{0^{\prime}}-E} . \\
& X-X^{0^{\prime}}=Y_{X / E^{0}}\left(E^{0^{\prime}}-E\right)
\end{aligned}
$$

Where $Y_{X / E}$ is the yield of biomass on ethanol $(\mathrm{g} / \mathrm{g})$.
When plotting the different curves, was it is possible to determine the yields of biomass on glucose, $Y_{X / G}$, on ethanol, $Y_{X / E}$ and also the yield ethanol on glucose, $Y_{E / G}$.

\subsection{Batch cultures \\ 3.1.1. Selection of Saccharomyces cerevisiae strain}

Table (3) summarizes the kinetic parameters resulted from the three tested strains. These strains present the same diauxic growth profile. Presence of glucose concentration was important at the beginning of the fermentation; the yeast growth became rapidly high and attained a growth rate of $0.27 \mathrm{~h}^{-1}$ for $S$. cerevisiae Sc 2 and $0.32 \mathrm{~h}^{-1}$ for $S$. cerevisiae Sc 3 (Table 3). Glucose suppressed the respiration of yeast and the accumulation of ethanol was observed. A low biomass yield $(0.12$ and $0,17 \mathrm{~g}$ of dry matter per gram of consumed glucose for $S$. cerevisiae Sc 2 and for $S$. cerevisiae $S c 3$, respectively) pointed out a predominant fermentation metabolism. Once glucose was depleted, after few hours of adaptation to the new environment, a second stage of rapid growth took place that corresponds to the use of ethanol.

During this second stage, a growth rate with values of 0.06 and $0.11 \mathrm{~h}^{-1}$ for $S$. cerevisiae $S c 1$ and for $S$. cerevisiae Sc 3, respectively, was obtained and a high yield with values of 0.38 and 0.50 ( $\mathrm{g}$ of dry matter per gram of consumed glucose) for $S$. cerevisiae $S c 2$ and for S.cerevisiae $S c 3$, respectively was obtained. These results are an indicator of ethanol assimilation. The vast majority of yeast strains consumed both maltose and maltotriose only after glucose depletion (Salema-Oom et al., 2005). Moreover, most yeast strains used maltotriose only after maltose was consumed, and very often trisaccharides were not completely consumed (Londesborough, 2001). The obtained results in Table (3) indicate that $S$. cerevisiae $\mathrm{Sc} 3$ showed the highest maximum specific growth rates on glucose, $\left(\mu_{\max }\right.$ glu $)$ and on ethanol, $\left(\mu_{\max }\right.$ eth $)$. The biomass yields on glucose $\left(Y_{X / G}\right)$ and on ethanol $\left(Y_{X / E}\right)$ were also the most important with the $S$. cerevisiae Sc 3. It had also relatively low yield of ethanol on glucose $\left(Y_{E / G}\right)$ of a value of $0.33(\mathrm{~g} / \mathrm{g})$. According to the obtained results $S$. cerevisiae Sc 3 was chosen for the next study. 
Table (3): The kinetic parameters of Saccharomyces cerevisiae strains.

\begin{tabular}{|l|c|c|c|}
\hline \multirow{2}{*}{ Kinetic parameters } & \multicolumn{3}{|c|}{ Saccharomyces cerevisiae } \\
\cline { 2 - 4 } & $S c 1$ & $S c 2$ & $S c 3$ \\
\hline$\mu_{\max \text { glu }}\left(\mathrm{h}^{-1}\right)$ & 0.28 & 0.27 & 0.32 \\
\hline$\mu_{\max \text { eth }}\left(\mathrm{h}^{-1}\right)$ & 0.06 & 0.08 & 0.11 \\
\hline$Y_{X / G}(\mathrm{~g} / \mathrm{g})$ & 0.17 & 0.12 & 0.17 \\
\hline$Y_{X / E}(\mathrm{~g} / \mathrm{g})$ & & & 0.50 \\
\hline$Y_{E / G}(\mathrm{~g} / \mathrm{g})$ & 0.50 & 0.38 & 0.33 \\
\hline
\end{tabular}

With : $\mu_{\max \text { glu }}$, Maximum specific growth rate on glucose, $\mu_{\max \text { eth }}$, Maximum specific growth rate on ethanol, $Y_{X / G}$ : yield biomass on glucose, $Y_{X / E}$ :

yield biomass on ethanol, $Y_{E / G}$ : yield ethanol on glucose.

Table (4): Summary of the kinetic parameters, maximum specific growth rates and yields, for the strain of $S$. cerevisiae $S c \boldsymbol{3}$ in the cultures media $\mathrm{C}^{\circ} 1$ and $\mathrm{C}^{\circ} 2$ as described in Table $2\left(\mathrm{~N}^{\circ} 3\right)$.

\begin{tabular}{|l|l|l|l|}
\hline \multirow{2}{*}{ Kinetic parameters } & \multicolumn{3}{|c|}{ Culture media } \\
\cline { 2 - 4 } & $\mathrm{C}^{\circ} 1$ & $\mathrm{C}^{\circ} 2$ & Results * \\
\hline$\mu_{\max \text { glu }}\left(\mathrm{h}^{-1}\right)$ & 0.56 & 0.53 & 0.32 \\
\hline$\mu_{\max \text { eth }}\left(\mathrm{h}^{-1}\right)$ & 0.11 & 0.10 & 0.11 \\
\hline$Y_{X / G}(\mathrm{~g} / \mathrm{g})$ & 0.15 & 0.18 & 0.17 \\
\hline$Y_{X / E}(\mathrm{~g} / \mathrm{g})$ & 0.44 & 0.50 & 0.50 \\
\hline$Y_{E / G}(\mathrm{~g} / \mathrm{g})$ & 0.42 & 0.37 & 0.33 \\
\hline
\end{tabular}

$\mu_{\max \text { glu }}$ and $\mu_{\max \text { eth }}$ are the maximum specific growth rates on glucose and on

ethanol respectively. $Y_{X / G}, Y_{X / E}$ and $Y_{E / G}$ are the the yields biomass on glucose, biomass on ethanol and ethanol on glucose respectively. ${ }^{*}$ For comparison, results come from table 3 .

Table (5): The yield, productivity and the percentages of the two flora observed during the steady state of different continuous cultures.

\begin{tabular}{|c|c|c|c|c|}
\hline \multirow[t]{2}{*}{ Cultures } & Yield $Y_{X / G}$ ) & Productivity & K. marxianus & S. cerevisiae \\
\hline & $(g / g)$ & g/l.h & $\%$ & $\%$ \\
\hline $\begin{array}{l}\text { continuous-I } \\
\text { Permeate + glucose + Y.E 0.5g/l }\end{array}$ & 0.47 & 0.8 & 80 & 20 \\
\hline $\begin{array}{l}\text { continuous-II } \\
\text { Permeate + Hydrolysate A }+ \text { Y.E } \\
\text { 0.5g/l }\end{array}$ & 0.43 & 0.7 & 100 & $\mathbf{0}$ \\
\hline $\begin{array}{l}\text { continuous-III } \\
\text { Permeate + Hydrolysate B + Y.E 0.5g/l }\end{array}$ & 0.48 & 0.9 & 13 & 87 \\
\hline $\begin{array}{l}\text { continuous-III-bis } \\
\text { Permeate+ Hydrolysate B + Y.E 0.1g/l }\end{array}$ & 0.44 & 0.8 & 64 & 36 \\
\hline
\end{tabular}




\subsubsection{Growth kinetics of Kluyveromyces marxianus on whey permeate supplied with glucose}

The influence of glucose that comes from starch hydrolysates on the assimilation of lactose by $K$. marxianus was studied. In both cases, $K$. marxianus presents an exponential growth up to the exhaustion of substrates (lactose and glucose). Whatever the nature of the carbohydrate source (lactose or glucose) used in the subculture, $K$. marxianus began by using glucose, and then the assimilation of lactose started even if the fermentation medium still contains about $3.5 \mathrm{~g} / \mathrm{l}$ of glucose. The assimilation of glucose by $K$. marxianus started after 4 hours of incubation in the case where the subculture was realized on lactose, and 1 hour of incubation in the case where the subculture was realized on glucose. The calculation of maximum specific growth rates gives $\mu_{\max }=0.42 \mathrm{~h}^{-1}$ and $0.37 \mathrm{~h}^{-1}$ if the subculture was realized on lactose and on glucose, respectively. Therefore, the values obtained for $\mu_{\max }$ in both cases were nearly similar.

3.1.3. Growth kinetics of Saccharomyces cerevisiae $S c 3$ on whey permeate supplied with starch hydrolysates (glucose)

The influence of the composition of the whey permeate on the growth of $S$. cerevisiae $S c 3$ was studied to find out if whey permeate could possibly contains inhibitors or be deficient in certain nutrients necessary for Saccharomyces growth. The maximal biomass concentration was identical in the two media $\mathrm{C}^{\circ} 1$ and $\mathrm{C}^{\circ} 2$ (Table 2) and it was $3.5 \mathrm{~g} / \mathrm{l}$. The biomass reached its maximal concentration after 15 hours of incubation in both media. The total assimilation of glucose was reached after 6 and 7 hours of incubation in the medium $\mathrm{C}^{\circ} 1$ and $\mathrm{C}^{\circ} 2$ (Table 2), respectively. The maximal ethanol production (3.9 $\mathrm{g} / \mathrm{l}$ and $3.4 \mathrm{~g} / \mathrm{l}$ ) was obtained after 6 and 7 hours of incubation in the medium $n^{\circ} 1$ and $n^{\circ} 2$, respectively. The obtained results indicated that there were no significant differences between the growth parameters for the two media $\mathrm{C}^{\circ} 1$ and $\mathrm{C}^{\circ} 2$ Table $2\left(\mathrm{~N}^{\circ} 3\right)$. The maximum specific growth rates on glucose and on ethanol $\left(\mu_{\max \text { glu }}\right.$ and $\mu_{\max }$ eth) for the two media $\mathrm{C}^{\circ} 1$ and $\mathrm{C}^{\circ} 2$ were identical (Table 4). The yields biomass on glucose, $Y_{X / G}$ and biomass on ethanol, $Y_{X / E}$ acquired on medium $\mathrm{n}^{\circ} 2$ are superior to those acquired on medium $\mathrm{n}^{\circ} 1$. Moreover, the yield of ethanol on glucose, $Y_{E / G}$, on medium $\mathrm{C}^{\circ} 2$ was less than that acquired on medium $\mathrm{C}^{\circ} 1$ (Table 4). The addition of Y.N.B to the medium therefore did not improve the performances of the culture. The results of the third column in the Table (4) indicate that medium $\mathrm{n}^{\circ} 2$ allows a better growth (higher in $\mu_{\max \text { glu }}, \mu_{\max }$ eth and excess yield) than the medium Y.N.B supplied only with glucose. As a result, the whey permeate supplied with nutrients necessary for the growth of $K$. marxianus $\left[\mathrm{FeCl}_{3},\left(\mathrm{NH}_{4}\right)_{2} \mathrm{SO}_{4}\right.$ and Y.E], allowed an optimum growth for $S$. cerevisiae. The obtained results therefore indicated that the whey permeate used in this study did not contain inhibitive elements.

\subsection{Continuous cultures}

Fig (1 and 2) present the growth kinetics acquired in the fermentation course of the two accomplished studies, continuous-I and continuous-II. At the steady state, there was no accumulation of sugar in the medium (lactose or glucose), and ethanol production was equal to zero. The yields of yeast on sugar $\left(Y_{X / G}\right)$

calculated from the final quantity of produced yeast, to the total quantity of consumed sugars (lactose and glucose), were equal to $0.47 \mathrm{~g} / \mathrm{g}$ and $0.43 \mathrm{~g} / \mathrm{g}$ for continuous-I and continuous-II, respectively (Table 5). The productivity (calculated as final quantity of produced yeast multiplied by the dilution rate) was equal to 0.8 and $0.7 \mathrm{~g} / \mathrm{l} . \mathrm{h}$ for continuous-I and continuous-II, respectively. It was found that in continuous-I, at the steady state, $K$. marxianus was represented 80 $\%$ of the total population while S. cerevisiae Sc 3 was represented only $20 \%$ (Table 5). In the continuous-II, the population of S. cerevisiae Sc 3 has completely exceeded by that of $K$. marxianus. The obtained percentages for the continuous-I were indeed inexact seen to the used methodology for the evaluation of the two yeasts (method of resistance to actidione). Because the evaluation of the population of $S$. cerevisiae $S c 3$ being accomplished by difference of the obtained populations on the medium with and without actidione, the difference between the two method was almost inexistent. The determined percentages by the X-Gal method in the case of the continuous-II were more reliable and consequently, they show that it was not possible to support in a stable way both strains in co- culture in the conditions of the continuous-I and continuous-II. The displacement of the population of $S$. cerevisiae $S c 3$ by the growth of $K$. 


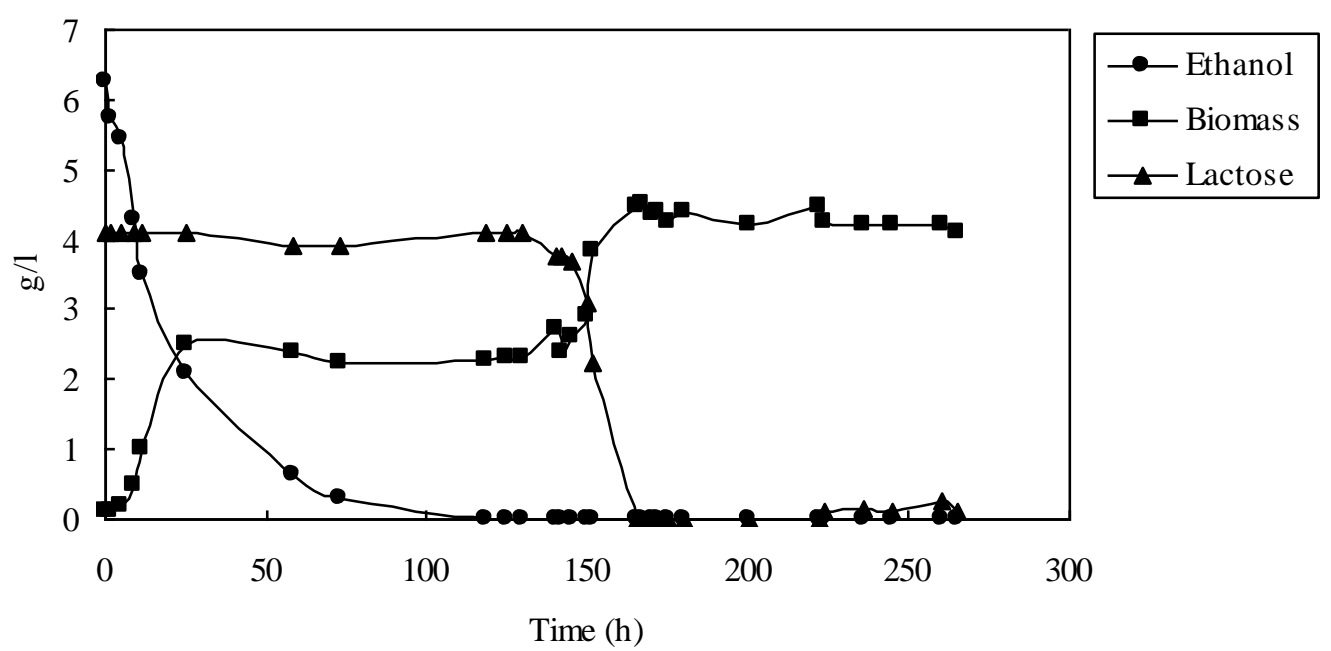

Fig. (1): Continuous culture I on whey permeate (lactose $5 \mathrm{~g} / \mathrm{l}$ ) supplied with glucose $5 \mathrm{~g} / \mathrm{l}$.

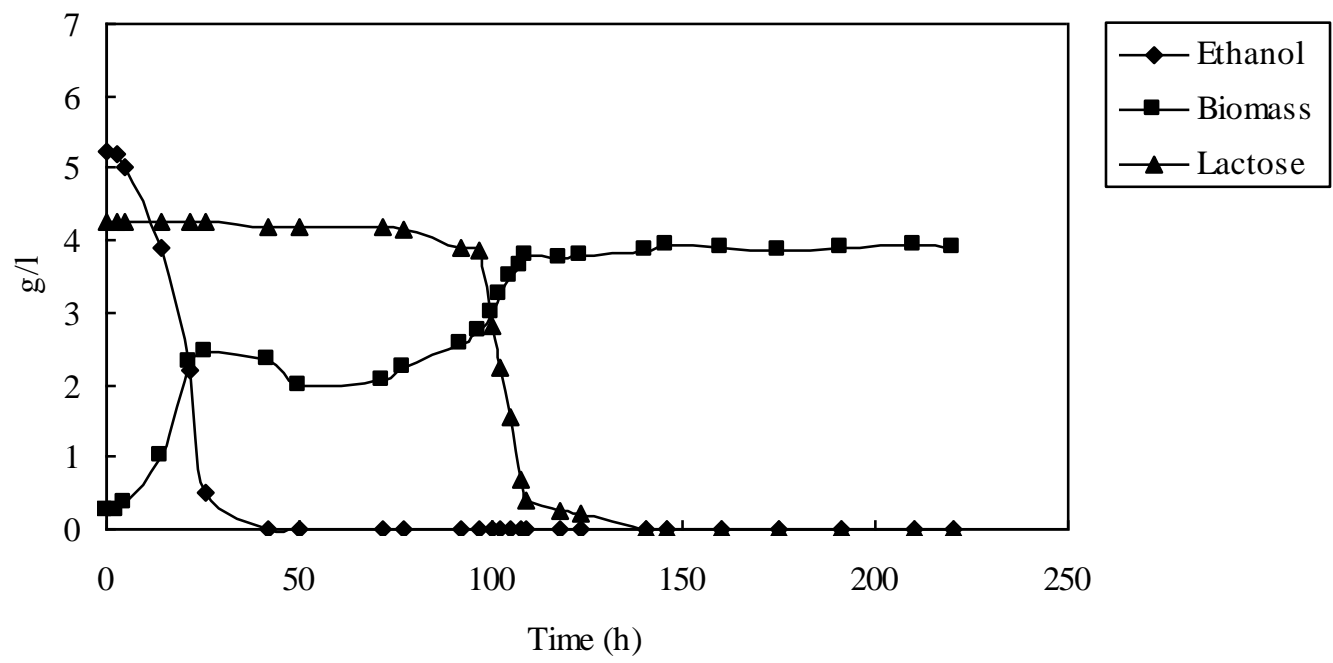

Fig. (2): Continuous culture II on whey permeate (lactose 5 g/l) supplied with starch hydrolysate 'A' (glucose $5 \mathrm{~g} / \mathrm{l}$ ). 
marxianus seems to be explained by the consumption of glucose of the medium, which was faster in the Kluyveromyces cells. Gasnier (1987) showed that in lactose-grown cells, glucose was transported in $K$. marxianus through a high affinity $\mathrm{H}^{+}$-sugar symporter $(\mathrm{Km}=0.09 \mathrm{mM})$, whereas a low-affinity transporter $(\mathrm{Km}=3.5 \mathrm{~mm})$ was utilized in glucose-grown cells. Compared with the values of the $\mathrm{Km}$ of transporters of glucose in $S$. cerevisiae cells $(\mathrm{Km}=1-5 \mathrm{~mm}$ and $\mathrm{Km}=$ $20-50 \mathrm{~mm}$ ), the capture of glucose from the medium is therefore accomplished with a higher affinity in the Kluyveromyces cells than in Saccharomyces cells. The impossibility of stabilizing a coculture on a mixed substrate containing whey permeate and glucose was the reason to test the effect of other carbohydrate sources than glucose. Starch hydrolysate "B", with high maltose content, was then tested with the whey permeate as a new mixed substrate. It is important to know that the maltose is assimilated only by Saccharomyces cells. The following fermentations of continuous-III and continuous-III-bis were performed for studying the behavior of the coculture in the presence of the new mixed substrate. Figure (3) presents the obtained kinetics in the course of continuous cultures. It was observed that there were no production of ethanol and accumulation of glucose in the culture medium. However, residual maltose in a constant concentration $(0.2 \mathrm{~g} / \mathrm{l})$ was found. A slight accumulation of lactose at the rate of 0.1 $\mathrm{g} / \mathrm{l}$ was also detected when the concentration of yeast extract in the feeding medium was reduced from 0.5 to $0.1 \mathrm{~g} / \mathrm{l}$. The yield of yeast on sugar $\left(Y_{X / G}\right)$ and the productivity for the continuous-III were equal to $0.48 \mathrm{~g} / \mathrm{g}$ and 0.9 g/l.h, respectively. In the case of continuous-
III-bis the yield $\left(Y_{X / G}\right)$ and the productivity were equal to $0.44 \mathrm{~g} / \mathrm{g}$ and $0.8 \mathrm{~g} / \mathrm{l} . \mathrm{h}$, respectively. The obtained results from continuous-III concerning the evaluation of the percentages of the two yeast strains by using the method X-Gal, indicated that $87 \%$ of the population belonged to the $S$. cerevisiae $S c 3$ and $13 \%$ of the population belonged to $K$. marxianus (Table 5). These results were unexpected.

If it is assumed that a theoretical yield $\left(\mathrm{Y}_{\mathrm{t}}\right)$ is equal to $0.5 \mathrm{~g} / \mathrm{g}$ (gram of $K$. marxianus produced per gram of consumed lactose), and knowing that, the total biomass $(\mathrm{X})$ becomes stable to a value of about $5 \mathrm{~g} / \mathrm{l}$ and there is no lactose residues in the medium (Fig. 3), therefore, the percentage of $K$. marxianus cells should at least be equal to $\frac{Y . S_{0}}{X} 100=50 \%$, where $S_{0}$ is the initial lactose concentration in the feeding and is equal to $5 \mathrm{~g} / \mathrm{l}$. This percentage can of course be higher if taking into account the partial or total assimilation of the available glucose in the medium by $K$. marxianus as in the case of continuous-I and continuous-II.

The obtained experimental percentages from continuous-III-bis were $36 \%$ for the $S$. cerevisiae Sc 3 and $64 \%$ for K. marxianus. These results are in agreement with the theoretical percentages if it is suppose that:

$(\mathrm{Y})$ is the yield of conversion of each of the sugars into biomass and it was assumed to be equal to $0.5 \mathrm{~g} / \mathrm{g}$.

(X) is the total biomass at the steady state which was experimentally measured as equal to $4.5 \mathrm{~g} / \mathrm{l}$ (Fig. 3), $\left(\mathrm{S}^{\circ}\right)$ is the initial sugars concentration in the feeding. $S$ is the concentration of residual sugars in the medium

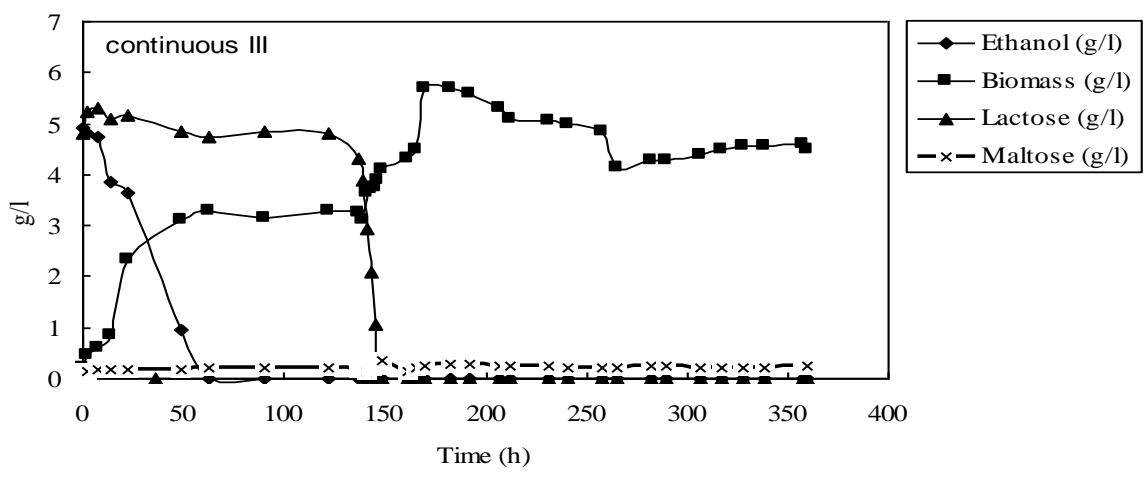

Fig. (3): Continuous culture III and III-bis on whey permeate (lactose 5 g/l) supplied with starch . 

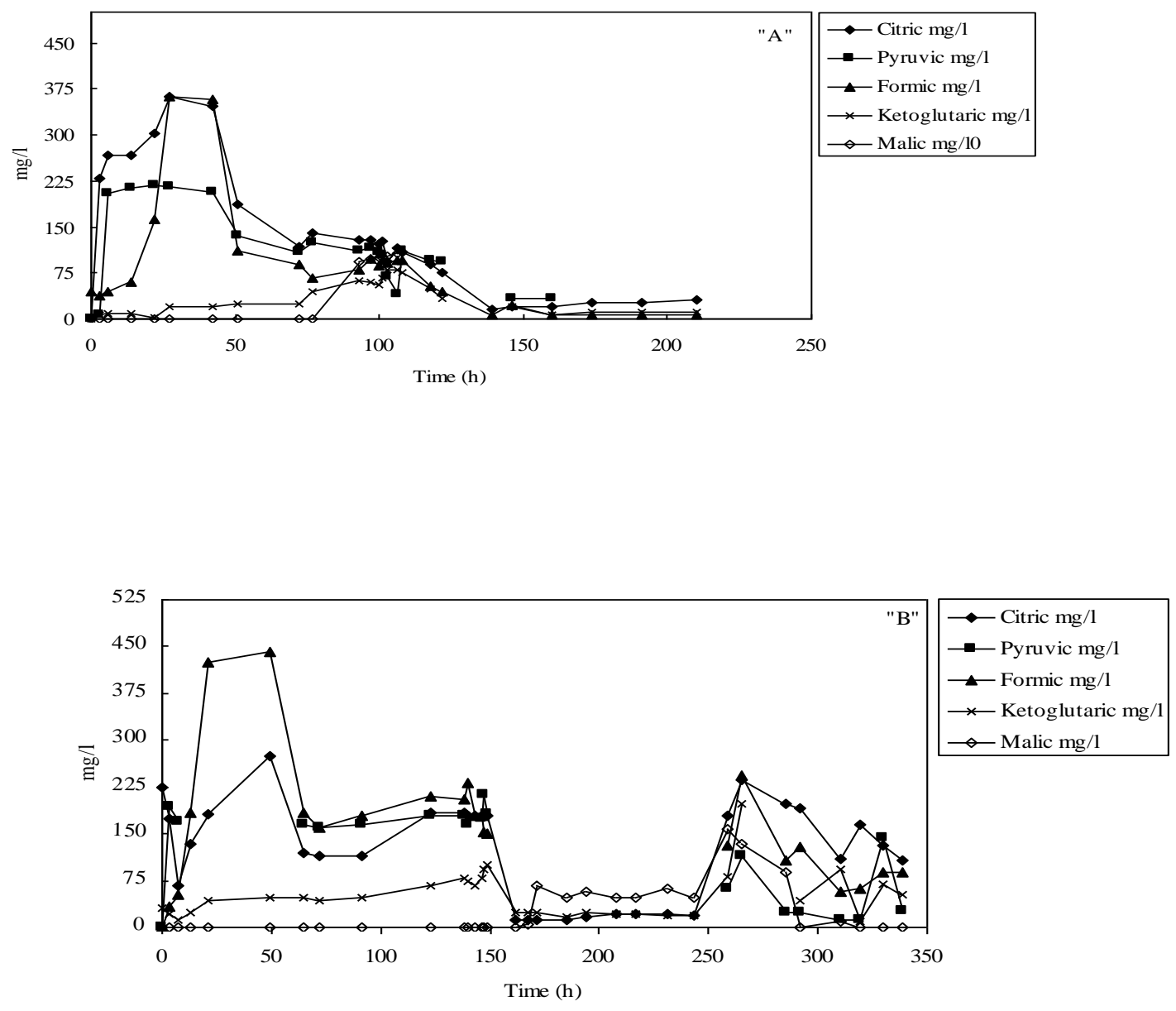

Fig. (4): Production of organic acids during "A" Continuous II and "B" during continuous III and IIIbis. Y.E=Yeast extract.

it is experimentally measured and it was equal to $0.1 \mathrm{~g} / \mathrm{l}$ for lactose and $0.2 \mathrm{~g} / \mathrm{l}$ for the maltose (Fig. 3). If it is assumed that $S$. cerevisiae Sc 3 only assimilates maltose while $K$. marxianus only assimilates lactose, the following theoretical percentages should be obtained:

$\%_{\text {th }}$ S.c $=\frac{Y\left(S_{o}-S\right)}{X} 100=\frac{0.5(3-0.2)}{4.5} 100=31.11 \%$.

$\%_{\text {th }}$ K.m $=\frac{Y\left(s_{o}-S\right)}{X} 100=\frac{0.5(5-0.1)}{4.5} 100=54.44 \%$.

These theoretical percentages are slightly less than the experimental percentages, which are wholly logical since they do not take into account the production of yeast from the consumption of glucose. According to the study of Busturia and Lagunas (1985), the system of transport of the maltose in the Saccharomyces exists in two forms with $\mathrm{Km}$ equal to 4 and $70 \mathrm{mM}$, respectively.
It was concluded that both forms of the maltose transport system were regulated by catabolite inactivation. Therefore, this system by the values of $\mathrm{Km}$ and by the mechanism of regulation looks like the system of transport of glucose in the same yeast. It would remain to define the influence of the maltose on the metabolism of lactose by $K$. marxianus since the results of the continuous-III gave in the steady state, $13 \%$ K. marxianus and to be compared with $100 \%$ acquired in the case of the continuous-II. On the other hand, when the concentration in yeast extract of the medium was reduced from 0.5 to 0.1 $\mathrm{g} / \mathrm{l}$, the metabolism of lactose by $K$. marxianus was once again performed in an usual manner: because $64 \%$ of the cells were produced, which is in agreement with the theoretical percentage. 


\subsection{Analysis of the evolution of the organic acids concentration}

The evolution of the concentration of several organic acids was followed during the course of the continuous fermentations II (Fig. 4A), continuous fermentations III and III-bis (Fig. 4B). These organic acids are Pyruvic acid, Formic acid, Citric acid, Malic acid, $\alpha$-Ketoglutaric acid. In the course of the batch fermentation of $S$. cerevisiae on ethanol, there was a massive production of the above mentioned organic acids. This production was always present but tends to become stable in the course of the continuous cultures. The addition of $K$. marxianus to the medium led to an important fall in the concentration of all acids, there was undoubtedly a consumption of these acids by such yeast. In the presence of maltose (continuous-III), this consumption could possibly cause an energy uncoupling at the cell level, and led to a poor conversion of lactose into biomass, which would explain the low percentage (13\% of cells) of produced $K$. marxianus. When the concentration of yeast extracts in the feeding was reduced to 0.1 $\mathrm{g} / \mathrm{l}$, the assimilation of the organic acids by $K$. marxianus was distinctly less important than in the case where yeast extract concentration was equal to $0.5 \mathrm{~g} / \mathrm{l}$. At a concentration of $0.1 \mathrm{~g} / \mathrm{l}$, the yeast extract, therefore, prevented the assimilation of acids by $K$. marxianus, and it followed that the metabolism of lactose was once again accomplished in an usual way, leading to a resumption of cells viability.

This study reveals that the strain $S$. cerevisiae Sc 3 was the most suitable among the three tested strains which has the most efficient cellular multiplication process. The importance of this work resides also in the transformation of two different agro-industrial wastes (whey permeate and starch hydrolysates) by two different yeast strains (S. cerevisiae Sc 3 and $K$. marxianus) in a stabilized coculture. Also, this kinetic study has presented the advantages of this coculture: the diversity and richness of the obtained biomass and the joint utilization of two agro-industrial wastes. The food industries will benefit by having available an alternative to the disposal of their wastes. The transformations of whey permeate and starch hydrolysates to a viable product such as single cell protein offers an effective solution to the environmental disposal problem of the two wastes.

\section{Acknowledgements}

I would like to thank Dr. Malik Haddadin from Jordan University, Amman-Jordan and Dr
Catherine Valance from Bongrain Gerard SA, Le Tholy-France for skilled technical and analytical assistance.

\section{REFERENCES}

Beausejour D., Leduy A. and Ramalho R.S. (1981). Batch cultivation of Kluyveromyces fragilis in cheese whey. Canadian Journal o f Chemical Engineering. 59: 522-526.

Belem M.A. and Lee BH. (1998). Production of bioingredients from Kluyveromyces marxianus grown on whey: an alternative. Crit Rev Food Sci Nutr. 38: 565-598.

Busturia A. and Lagunas R. (1985). Identification of two forms of the maltose transport system in Saccharomyces cerevisiae and their regulation by catabolite inactivation. Biochim. Biophys. Acta. 820: 324-326.

Carlotti A., Jacob F., Perrier J. and Poncet S. (1991). Yeast production from crude sweet whey by a mixed culture of Candida kefir LY496 and Candida valida LY497, Biotechnology Letters, 13: 437-440.

Compango C., Porro D., Smeraldi C. and Ranzi BM. (1995). Fermentation of whey and starch by transformed Saccharomyces cerevisiae cells. Appl. Microbiol. Biotechnol. 43: 822-825.

Cristiani-Urbina E., Netzahuatl-Munoz AR., Manriquez-Rojas F.J., Juarez-Ramirez C., Ruiz-Ordaz N. and Galindez-Mayer J. (2000). Batch and fed-batch cultures for the treatment of whey with mixed yeast cultures. Process Biochemistry. 35: 649657.

Cristiani-Urbina E., Ruiz-Ordaz N. and GalindezMayer J. (1997). Differences in the growth kinetic behaviour of Torulopsis cremoris in batch and continuous cultures. Biotechnology and Applied Biochemistry. 26: 189-194.

Gasnier B. (1987). Characterization of low- and high-affinity glucose transports in the yeast Kluyveromyces marxianus. Biochim. Biophys. Acta. 903: 425-433.

Ghaly A.E. and Kamal M. A. (2004). Submerged yeast fermentation of acid cheese whey for protein production and pollution potential reduction. Water Resource 38: 631-644.

Inchaurrondo V. A., Yantorno O. M. and Voget C.E. (1994). Yeast growth and Betagalactosidase production during aerobic batch cultures in lactose-limited synthetic medium. Process Biochemistry, 29: 47-54. 
Londesborough J. (2001). Fermentation of maltotriose by brewer's and baker's yeast. Biotechnol. Lett., 23: 1995-2000.

Lukondeh T., Ashbolt N. J. and Rogers P. (2003). Evaluation of Kluyveromyces marxianus as source of yeast autolysates. J Ind Microbiol. Biotechnol. 30: 52-56.

Lukondeh T., Ashbolt N.J. and Rogers P. L. (2005). Fed-batch fermentation for production of Kluyveromyces marxianus FII510700 cultivated on a lactose-based medium. J. Ind. Microbiol. Biotechnol., 32: 284-288.

Maniatis T., Fritsch E. F. and Sambrook J. (1982). Molecular Cloning. A Laboratory Manual. Cold Spring Harbor Laboratory.

Paul D, Mukhopadhyay R, Chatterjee BP and Guha AK. (2002). Nutritional profile of food yeast Kluyveromyces fragilis biomass grown on whey. Appl. Biochem. Biotechnol., 97: 209-218.

Salema-Oom M., Pinto V.V., Goncalves P. and Spencer-Martins I. (2005). Maltotriose utilization by industrial Saccharomyces Strains: Characterization of a new member of the-glucoside transporter family. Applied and Environmental Microbiology, 71: 50445049.

Schultz N., Lifung C., Achim H., Matthias R. and Christoph S. (2006). Microbial production of single-cell protein from deproteinized whey concentrates. Appl. Microbiol. Biotechnol., 69: 515-520.

Van der Walt J. P. (1970). The Yeast: A Taxonomic Study. Editor: Lodder J. NorthHolland Publishing Company.

\title{
أنتاج مادة حيوية بروتينية من مخلفات الصناعات الغذائية (الشرش والنشا)

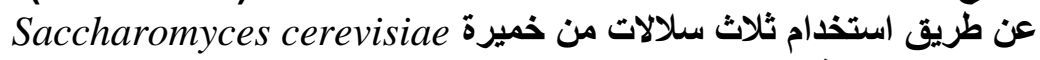

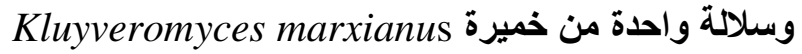

\author{
جمال صالح حدادين \\ قسم التغذية والصناعات الغذائية ـ كلية الزر اعة ـ جامعة مؤتة ـ الكرك ـ الأردن
}

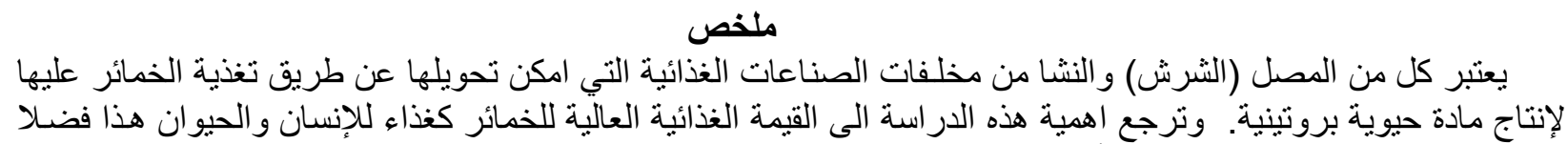

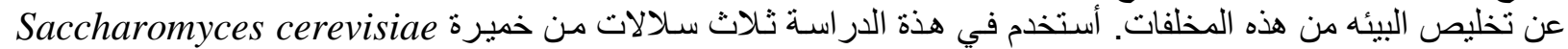

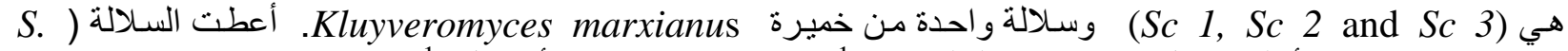
(cerevisiae Sc 3

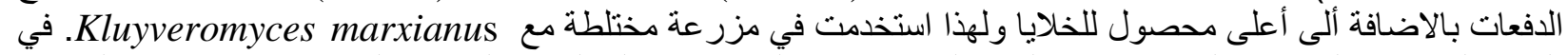

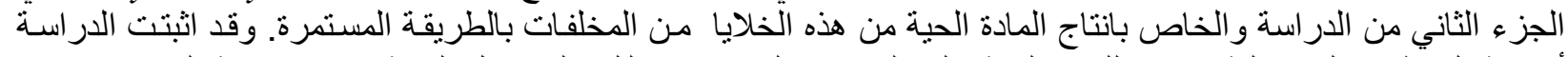

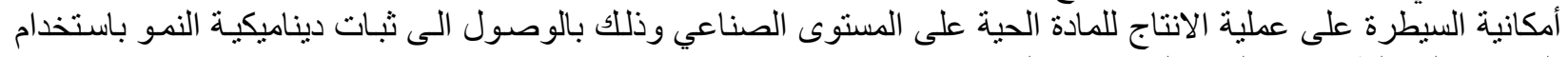

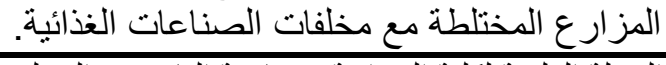

المجلة العلمية لكلية الزر اعة - جامعة القاهرة - المجلد (60) العدد الأول (ينـاير 2009 ) : 74-85. 